\title{
Evaluation of using veliger stage larvae for the preparation of metaphase spreads from the pacific abalone (Haliotis discus hannai)
}

\author{
Jae Hoon Choi ${ }^{1}$, Eun Jeong Kim ${ }^{1}$, Choul-Ji Park ${ }^{2}$, Yoon Kwon Nam ${ }^{1,3}$ and Seung Pyo Gong ${ }^{1,3, *}$ \\ ${ }^{1}$ Department of Fisheries Biology, Pukyong National University, Busan 48513, Korea \\ ${ }^{2}$ Genetics and Breeding Research Center, National Institute of Fisheries Science, Geoje 53334, Korea \\ ${ }^{3}$ Department of Marine-Biomaterials and Aquaculture, Pukyong National University, Busan 48513, Korea
}

Received August 22, 2020

Revised September 4, 2020

Accepted September 4, 2020

*Correspondence

Seung Pyo Gong

E-mail: gongsp@pknu.ac.kr

ORCID

https://orcid.org/0000-0002-9358-9568

\begin{abstract}
Karyotype analysis is a major work in the process of triploid abalone production for the purpose of productivity and quality improvement. However, the metaphase spreads for karyotype analysis have been prepared just from the larvae at trochophore stage, which has restricted the spectrum of sample correction inhibiting more efficient analysis. Here, we investigated the feasibility of preparing metaphase spreads from the larvae at veliger stage that is the next developmental stage of trochophore. For this, diploid and triploid larvae at trochophore and veliger stages from Pacific abalone (Haliotis discus hannai) were subjected to metaphase spread preparation and its efficiencies were measured and compared each other. As the results, although the efficiencies of metaphase spread preparation were significantly lower in the larvae at veliger stage compared to the ones at trochophore stage regardless of ploidy status, we found that the preparation of metaphase spreads, which showed the clear chromosomal images containing the normal number of chromosomes, was possible from the veliger stage larvae. On the other hands, all larvae used in this study regardless of developmental stage and ploidy did not show colchicine sensitivity. Moreover, no significant difference was observed in cell cycle distribution of the cells comprising larvae between two developmental stages regardless of ploidy status. These suggested that the details of protocol to prepare metaphase spreads from abalone larvae should be optimized depending on its developmental stages. Taken together, we demonstrated the feasibility of preparing metaphase spreads from $H$. discus hannai veliger stage larvae for karyotype analysis.
\end{abstract}

Keywords: abalone, karyotyping, metaphase spread, ploidy, veliger

\section{INTRODUCTION}

Pacific abalone (Haliotis discus hannai) is one of the noticeable marine gastropods as a food source in eastern Asia (Wang et al., 2015). Thus, it has been subjected to a number of studies regarding an improvement of its productivity and quality through selective and genetic breeding technologies (Elliott., 2000). One example is the production of triploid abalone by artificial manipulation of the fertilized eggs (Park et al., 2018). In triploid abalone, due to the presence of one additional haploid chromosome-set, homologous chromosome paring and 
equivalent segregation does not happen clearly during the meiosis of its germ cells, which finally causes infertility or sex maturation delay (Arai et al., 2001; Piferrer et al., 2009; Dheilly et al., 2014). It makes triploid abalone consume more energy in somatic growth instead of in sexual maturation, which eventually contributes to an increase of its value as a food resource (Allen and Downing, 1986).

In the process of this technology, karyotype analysis that analyzes the mechanical traits of chromosome sets is a major work with the ploidy identification using a flow cytometry, and it necessarily requires the preparation of metaphase spreads. Previously, many karyotype analyses were reported from various abalone species; $H$. discus hannai (Jee and Chang, 2012; Ryu et al., 2018), $H$. rufescens (Gallardo-Escárate et al., 2004), H. corrugate (Gallardo-Escárate and del Río-Portilla, 2007), and H. fulgens (Hernandez-Ibarra et al., 2004). Although metaphase spread preparation could be done from the cultured mantle tissue of adult abalone (Ryu et al., 2018), in most cases, metaphase spreads were prepared from the developing larvae, especially the ones at trochophore stage. Trochophore stage larvae, on the basis of the results from the previous studies, are accepted as a good ingredient for the preparation of metaphase spreads for karyotype analysis since using them was able to provide a sufficient number of metaphase spreads which had the clear chromosomal images that are essential for accurate karyotype analysis (Gallardo-Escárate et al., 2004; Gallardo-Escárate and del Río-Portilla, 2007; Wang et al., 2015). This made the researchers conventionally use trochophore stage larvae for karyotype analysis in abalone and thus none of studies has demonstrated the feasibility of using the larvae at other developmental stages beside trochophore for the preparation of metaphase spreads. This has hampered efficient karyotype analysis in this species by limiting the spectrum of sample correction.

For this reason, we, in this study, evaluated the feasibility of preparing metaphase spreads from the larvae at veliger stage and compared the efficiency of metaphase spread preparation between trochophore and veliger stage larvae. Considering that the karyotype analysis in abalone is usually used in triploid production, we produced diploid and triploid abalone by artificial insemination and artificial induction, respectively, and both were used for metaphase spread preparation at two different developmental stages. Furthermore, colchicine sensitiv- ity of the larvae and cell cycle distribution of the cells comprising the larvae were examined to infer the reason of efficiency difference in metaphase spread preparation according to developmental stages of the larvae.

\section{MATERIALS AND METHODS}

\section{Artificial fertilization and triploid induction}

Three-years-old Pacific abalones ( $H$. discus hannai), which were managed in Genetics and Breeding Research Center, National Institute of Fisheries Science, Geoje, Republic of Korea, were used as brood abalones in this study. Artificial fertilization was performed according to the method from Lee et al. (Lee et al., 2019). Briefly, mature abalone were induced to release eggs and sperm by the conventional method of air exposure followed by ultraviolet (UV)-treated seawater treatments. Sperms were stored in $14^{\circ} \mathrm{C}$ water bath until fertilization, and the eggs collected were washed three times with $1 \mu \mathrm{m}$-filtered seawater at $18-19^{\circ} \mathrm{C}$. For artificial fertilization, about 10,000 eggs and 100,000 to 120,000 sperm were mixed and then washed with $1 \mu \mathrm{m}$-filtered seawater at $18^{\circ} \mathrm{C}$ for 2 minutes. After that, the fertilized eggs were transferred to the bath containing $1 \mu \mathrm{m}$-filtered seawater at $20^{\circ} \mathrm{C}$ for incubation. For triploid induction, the fertilized eggs at 11 minutes after fertilization were subjected to cold shock treatment at $1^{\circ} \mathrm{C}$ for 14 minutes to block the first polar body extrusion. After the cold shock treatment, the fertilized eggs were incubated in the bath containing $1 \mu \mathrm{m}$-filtered seawater at $20^{\circ} \mathrm{C}$.

\section{Metaphase spread preparation}

The larvae at trochophore and veliger stages were retrieved at 16-18 hours post fertilization (hpf) and 28-30 hpf, respectively. They were separately transferred in 40 $\mathrm{mL}$ plastic containers (Histoplex ${ }^{\mathrm{TM}}$ Histology Containers; Thermo fisher scientific, Rockford, IL, USA) and treated with $0.05 \%$ (w/v) colchicine (Sigma-Aldrich, St. Louis, MO, USA) dissolved in $0.22 \mu \mathrm{m}$-filtered seawater at $20^{\circ} \mathrm{C}$ for 4 hours. The larvae treated with colchicine were transferred into $15 \mathrm{~mL}$ tubes (Corning Life Science, Corning, NY, USA) and anesthetized by placing them onto ice for 5 minutes. They were washed two times with $5 \mathrm{~mL}$ filtered seawater to remove the rest of colchicine and then, immersed in $3 \mathrm{~mL} 0.075 \mathrm{M} \mathrm{KCl}$ (Sigma-Aldrich) for 1 hour. Finally, the larvae were fixed in $2 \mathrm{~mL}$ cold Carnoy solution 
[methanol (Duksan, Ansan, Korea):acetic acid (Duksan) = 3:1] for 1 hour with the regular solution changes every 20 minutes. After fixation, $1 \mathrm{~mL}$ acetic acid was added (final ratio of methanol and acetic acid $=1: 1$ ) and the fixed larvae were dissociated by gentle pipetting of about 40 times. After that, the composition of Carnoy solution was adjusted again to the original one (methanol:acetic acid $=3: 1)$ and the dissociated cells were dropped on the clean slide glasses, which were previously immersed in $50 \%(\mathrm{v} / \mathrm{v})$ acetic acid, wiped out with tissues and stored in $70 \%(\mathrm{v} / \mathrm{v})$ ethanol (Duksan) at $4^{\circ} \mathrm{C}$, to prepare metaphase spreads. For staining chromosomes, the slide glasses were completely dried at room temperature and stained with Giemsa solution containing 10\% (v/v) Giemsa stain (Gibco, Grand Island, NY, USA) in Gurr's buffer (Gibco) for 7 minutes at room temperature. After washing with distilled water and drying in air at room temperature, the slides were observed under a microscope. For calculation of percentage of metaphase spreads, first, the pictures of 30 spots from three slides, which were randomly selected and non-overlapped, were taken at $\times 200$ magnification using Motic image plus 2.0 software (Motic, Hong Kong, China) and the numbers of cells and metaphase spreads on the 30 spot pictures were counted. Then, the percentage of metaphase spreads were calculated as follow: the number of metaphase spreads/the number of cells and metaphase spreads $\times 100$.

\section{Measurement of colchicine sensitivity}

To evaluate colchicine sensitivity, diploid and triploid larvae at two developmental stages, trochophore and veliger, were treated or not with $0.05 \%(\mathrm{w} / \mathrm{v})$ colchicine dissolved in $0.22 \mu \mathrm{m}$-filtered seawater at $20^{\circ} \mathrm{C}$ for 4 hours. After that, they were washed with the filtered seawater two times and the ciliary movement of the larvae was observed under the microscope as a parameter of colchicine sensitivity. The number of larvae that showed ciliary movement were visually counted and the value was represented as the percentage of a total number of larvae in each treatment group.

\section{Analysis of cell cycles}

DNA contents of the cells comprising larvae were analyzed with CyStain ${ }^{\circledast}$ PI Absolute T (Partec, Münster, Germany) according to manufacturer's instructions. In brief, the larvae stored at $-70^{\circ} \mathrm{C}$ were transferred in a new 1.5
$\mathrm{mL}$ tube containing $500 \mu \mathrm{L}$ extraction buffer. After homogenization with handy tissue homogenizer (Biofact, Daejeon, Korea), the homogenized sample was filtered through CellTrics ${ }^{\circledR} 30 \mu \mathrm{m}$ (Partec) equipped to the top of $3.5 \mathrm{~mL}$ sample tube and the filtered sample was stained with $2 \mathrm{~mL}$ PI staining solution for 40 minutes in the dark. After staining, DNA contents of the sample were analyzed with CyFlow ${ }^{\circledR}$ Cube 6 (Partec). The ratios of the cells at each of three major cell cycle phases including G0/G1, $\mathrm{S}$ and G2/M were determined by partitioning the cellular DNA content frequency histograms using CyFlow ${ }^{\circledR}$ (Partec) software program with a slight reference to a previous report (Pozarowski and Darzynkiewicz, 2004).

\section{Statistical analysis}

The data regarding percentage of metaphase spreads, colchicine toxicity test and cell cycle analysis were expressed as mean \pm standard deviation of at least three independent experiments. Statistical analyses were performed with SPSS program (SPSS, Chicago, IL, USA). When analysis of variance (ANOVA) detected a significant main effect, the Duncan method was used to compare the treatments. Significant differences were determined when $p<0.05$.

\section{RESULTS}

\section{Efficiency of metaphase spread preparation according to developmental stages of larvae}

To evaluate quantitatively the availability of veliger stage larvae for preparing metaphase spreads, we performed metaphase spread preparation using both diploid and triploid larvae at trochophore and veliger stages and compared the efficiencies of metaphase spread preparation among one another. As the results, we observed significant differences in the efficiency of metaphase spread preparation by developmental stages of larvae (Fig. 1). Percentages of metaphase spreads were significantly higher in trochophore stage larvae than in veliger stage ones regardless of ploidy status $[32.7 \pm 4.4 \%$ (27.0 to $37.7 \%$ in raw data) and $32.7 \pm 6.1 \%$ (25.8 to $40.1 \%$ in raw data) in diploid and triploid trochophore larvae, respectively vs. $19.3 \pm 9.0 \%$ (11.5 to $29.6 \%$ in raw data) and 17.1 $\pm 8.0 \%$ ( 10.2 to $28.2 \%$ in raw data) in diploid and triploid veliger stage larvae, respectively, $p<0.05$ ]. This indicated that the preparation of metaphase spreads from veliger 


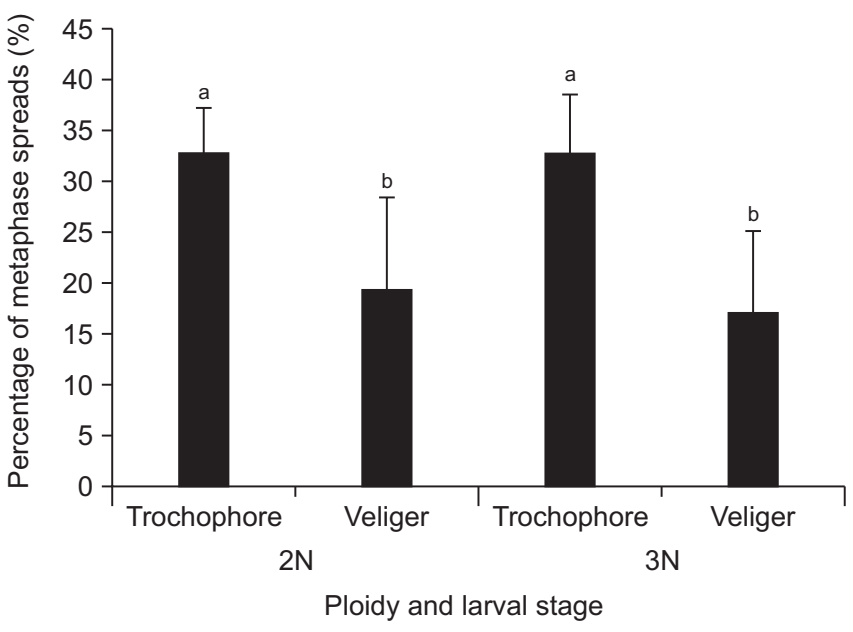

Fig. 1. Comparison of the efficiency of metaphase spread preparation from Haliotis discus hannai larvae between two different developmental stages. Metaphase spreads were prepared from diploid or triploid larvae at trochophore or veliger stage and the ratios of metaphase spreads out of total cells were measured. Percentage of metaphase spreads was significantly higher in trochophore compared to veliger stage larvae regardless of ploidy status. All values are expressed as mean \pm standard deviation of five independent experiments. ${ }^{a b}$ Different letters indicate significant differences $(p<0.05)$. stage larvae was possible even though its efficiencies were relatively low compared to those from trochophore stage larvae.

\section{Normality of metaphase spreads in regard to the number of chromosome sets}

The number of chromosome sets was confirmed as 36 and 54 chromosomes in diploid and triploid larvae, respectively, and the representative images of the chromosome sets were presented in Fig. 2. To evaluate the normality of metaphase spreads in regard to the number of chromosome sets by developmental stages of larvae, we counted the number of chromosomes in 30 metaphase spreads from each group and calculated the percentage of the cells that had the normal number of chromosomes. As shown in Fig. 3, the normality in chromosome number was similar between two developmental stages in both diploid and triploid larvae but the difference by ploidy was significant regardless of developmental stage of larvae (54.3\% and $48.6 \%$ in diploid larvae at trochophore and veliger stage, respectively vs. $32.9 \%$ and $30.0 \%$ in triploid larvae at trochophore and veliger stage, respectively).

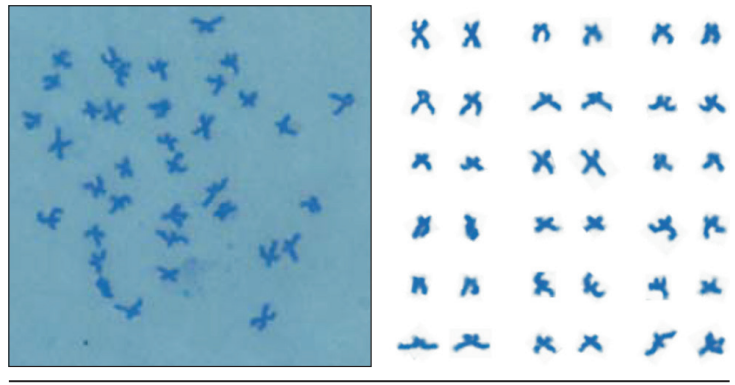

Trochophore $2 \mathrm{~N}=36$

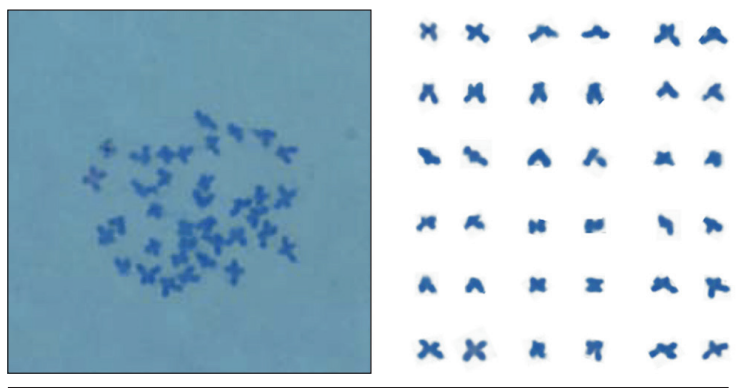

Veliger $2 \mathrm{~N}=36$
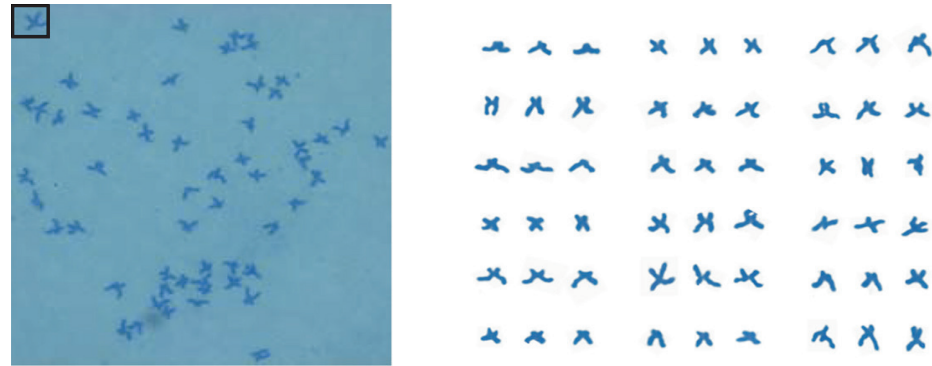

Trochophore $3 \mathrm{~N}=54$
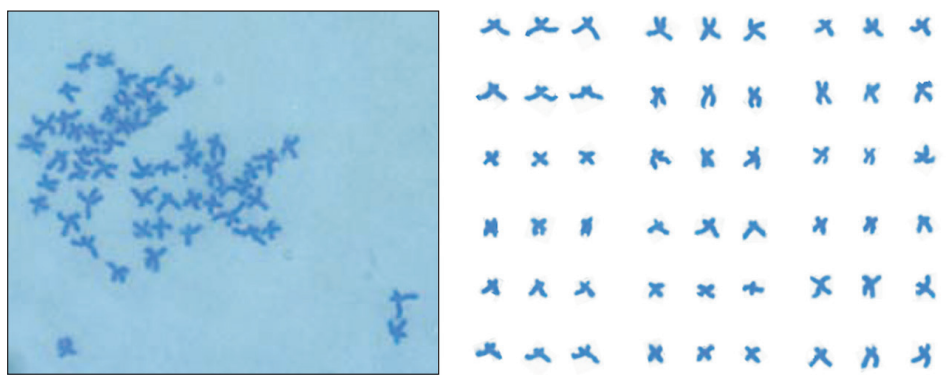

Veliger $3 \mathrm{~N}=54$

Fig. 2. Representative images of the chromosome sets derived from diploid and triploid Haliotis discus hannai larvae at two developmental stages, trochophore and veliger. Homologous chromosome sets were arranged based on the morphology of each chromosomes. The number of chromosomes was 36 and 54 in diploid and triploid larvae, respectively, regardless of developmental stage. Square box in the picture of metaphase spread from triploid trochophore larvae indicates the chromosome that got out of a single picture and thus were added artificially. 

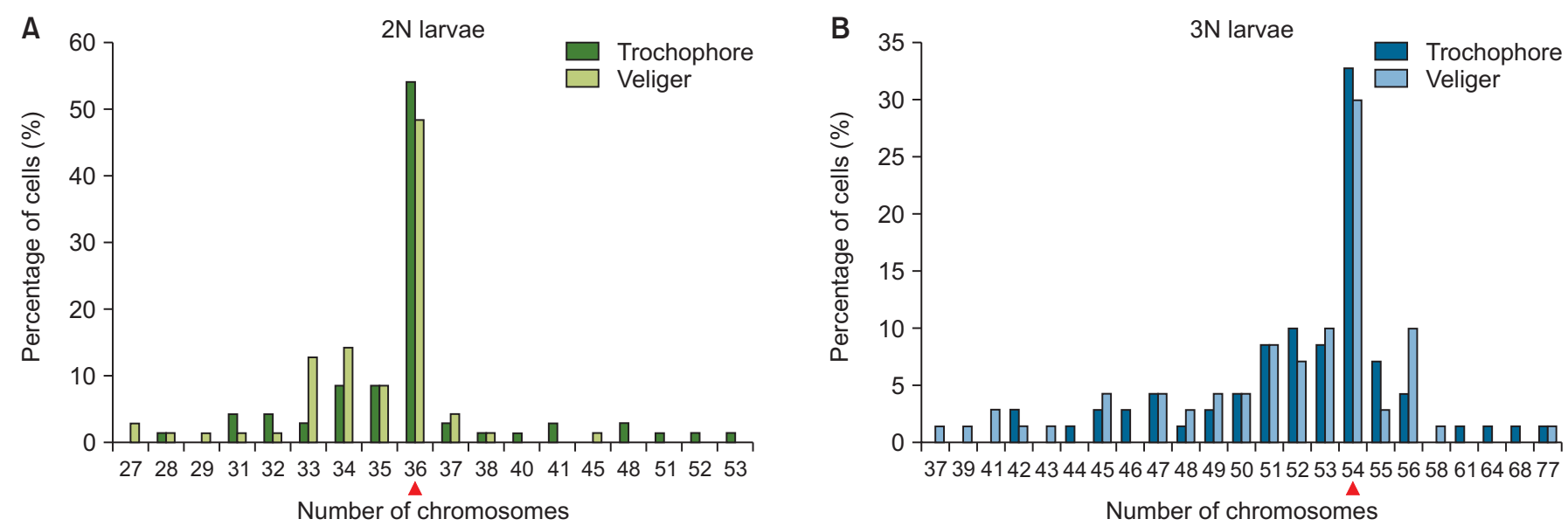

Fig. 3. The normality of chromosome number by developmental stage of Haliotis discus hannai diploid (A) and triploid (B) larvae. From 30 cells, percentage of the cells that had the normal number of chromosome sets was calculated. The arrow heads indicate the normal number of chromosome sets in diploid and triploid larvae.

A

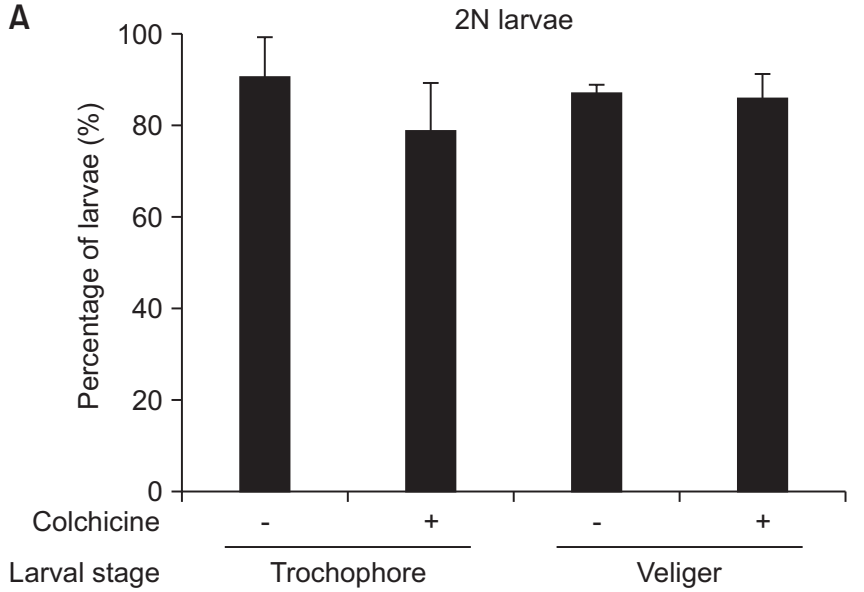

B

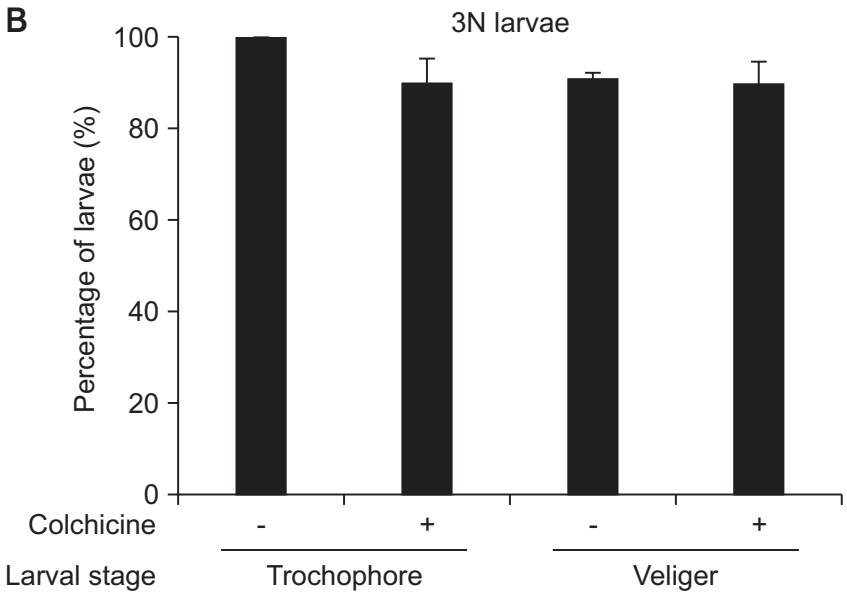

Fig. 4. Evaluation of colchicine sensitivity of Haliotis discus hannai diploid and triploid larvae at two developmental stages, trochophore and veliger. After the larvae were treated with colchicine or not, the number of larvae that showed ciliary movement were visually counted and its percentages were calculated. No significant difference was detected among all treatment groups in both diploid (A) and triploid (B) larvae. All values are expressed as mean \pm standard deviation of three independent experiments.

\section{Colchicine sensitivity}

As an effort to find the reason why the efficiency of metaphase spread preparation was different depending on developmental stage of abalone larvae, colchicine sensitivity of the larvae at two different developmental stages was examined. As shown in Fig. 4A, diploid larvae did not show any difference in ciliary movement according to colchicine treatment regardless of developmental stage. In trochophore, $90.8 \pm 8.3 \%$ and $78.9 \pm 10.2 \%$ larvae showed ciliary movement in control and colchicinetreated larvae, respectively, and in veliger, $87.1 \pm 2.0 \%$ and $86.0 \pm 5.3 \%$ larvae showed. Likewise, no significant difference was observed in the results from triploid larvae
(Fig. 4B). The percentage of trochophore stage larvae that showed ciliary movement was $100 \%$ and $90.1 \pm 5.3 \%$ in control and colchicine-treated ones, respectively, and in veliger, those were $91.1 \pm 1.1 \%$ and $90.0 \pm 4.9 \%$ in the same order. No other phenotypic side effects were observed during and after colchicine treatment.

\section{Cell cycle distribution of the cells comprising the larvae}

As an another approach to infer the reason of efficiency difference of metaphase spread preparation by developmental stage of larvae, cell cycle distribution of the cells comprising the larvae was investigated and compared be- 
tween two different developmental stages in both diploid and triploid larvae. Moreover, the effects of colchicine treatment on the cell cycle distribution of larvae were also examined. As the results, a large portion of the cells comprising the larvae corresponded to G0/G1 phase of cell cycle and relatively-small portions corresponded to $S$ or $\mathrm{G} 2 / \mathrm{M}$ phase regardless of developmental stage and colchicine treatment in both diploid and triploid larvae. As shown in Fig. 5, no significant difference was detected in the percentages of the cells at each cell cycle phases according to developmental stage regardless of ploidy and colchicine treatment. In contrast to this, colchicine treatment induced significant changes in cell cycle distribution of the cells comprising the larvae. After colchicine treatment, the ratios of the cells at G0/G1 phase were significantly decreased in all larvae regardless of both developmental stage and ploidy $(64.1 \pm 4.0 \%$ vs. $57.5 \pm 1.5 \%$ and $66.7 \pm 1.6 \%$ vs. $56.4 \pm 1.9 \%$ at trochophore and veliger, respectively, in diploid; $69.3 \pm 0.8 \%$ vs. $61.7 \pm 2.3 \%$ and $72.1 \pm 2.7 \%$ vs. $60.4 \pm 3.7 \%$ at trochophore and veliger, respectively, in triploid). On the other hand, the ratios of the cells at G2/M phase were significantly increased by colchicine treatment in all larvae regardless of both developmental stage and ploidy $(13.8 \pm 2.5 \%$ vs. $22.8 \pm 1.1 \%$ and $14.7 \pm 2.9 \%$ and $27.0 \pm 2.4 \%$ at trochophore and veliger, respectively, in diploid; $12.0 \pm 2.0 \%$ vs. $22.9 \pm 4.2 \%$ and $10.1 \pm 2.2 \%$ vs. $21.0 \pm 1.4 \%$ at trochophore and veliger, respectively, in triploid). In case of $S$ phase, the ratios of the cells were not influenced by colchicine treatment in all larvae tested.

\section{DISCUSSION}

In this study, we confirmed that metaphase spreads for karyotype analysis could be prepared from $H$. discus hannai larvae at veliger stage. In abalone, the veliger stage, as the next developmental stage of trochophore, has a longer developmental period compared to trochophore stage (Chung et al., 2011). This will allow the researchers to use the veliger stage larvae to verify the karyotype normality at the prolonged time when artificial breeding technologies including triploid production are performed. In this regard, it will be useful to test the availability of the veliger stage larvae at the other developmental time points beside $28-30 \mathrm{hpf}$ tested in this study for the preparation of metaphase spreads.

Although we confirmed the availability of veliger stage larvae on metaphase spread preparation, its efficiencies were significantly low compared to those from trochophore stage larvae. Previously, one report regarding fish demonstrated that the efficiency of metaphase spread preparation was altered according to species and developmental stages of larvae (Karami et al., 2015) but, to our knowledge, no report on this subject has been published yet in the gastropods. To reveal the reason of this result, we first tested colchicine sensitivity of the larvae on the
A

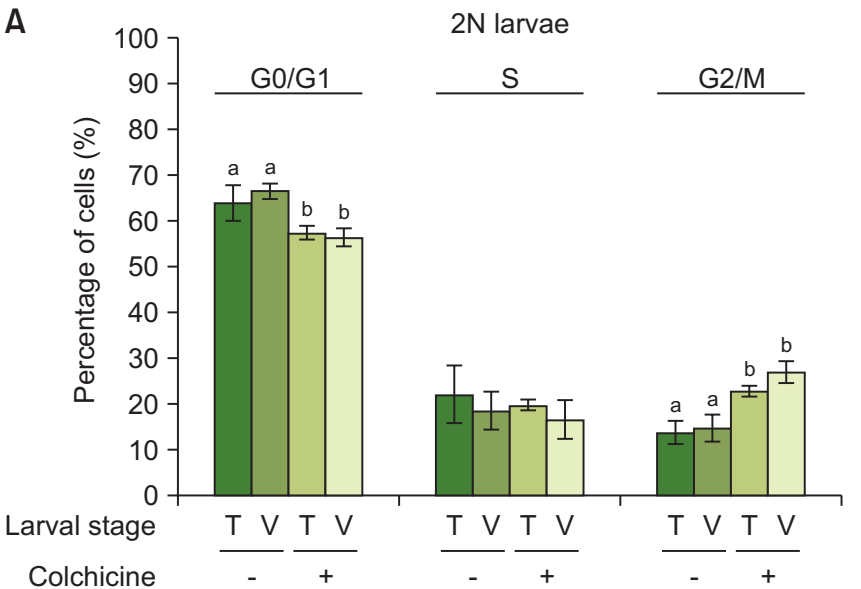

B

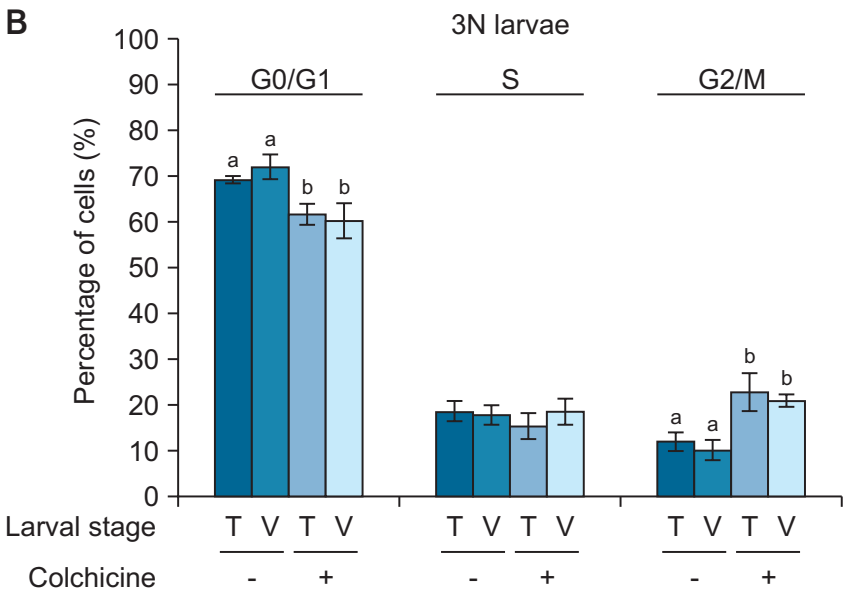

Fig. 5. Analysis of cell cycle distribution of the cells comprising Haliotis discus hannai diploid (A) and triploid (B) larvae at two developmental stages. DNA contents of the cells derived from the larvae were measured by flow cytometry and the ratios of the cells in each cell cycle phases were calculated. No significant difference in cell cycle distribution was observed by developmental stage of the larvae regardless of ploidy status. After colchicine treatment, however, the portions of G0/G1 and G2/M phases were decreased and increased, respectively, regardless of both developmental stage and ploidy status. All values are expressed as mean \pm standard deviation of three independent experiments. ${ }^{a, b}$ Different letters indicate significant differences $(p<0.05)$. T: trochophore, V: veliger. 
basis of ciliary movement. Colchicine, which blocks the assembly and polymerization of microtubules, is generally used for metaphase spread preparation (Leung et al., 2015) but its use at high concentration is able to reduce the survival rate of developing embryos (Ferm, 1963; Yang et al., 2006). Thus, we assumed that the efficiency difference of metaphase spread preparation by larval stage was caused by the different sensitivity of the larvae on colchicine exposure depending on developmental stage and thus more cell death in veliger stage larvae relative to trochophore by colchicine exposure might draw less efficiency of metaphase spread preparation. However, all larvae tested in this study did not show any colchicine sensitivity at least in terms of ciliary movement indicating that colchicine did not contribute significantly to the efficiency difference of metaphase spread preparation by developmental stage. Nevertheless, additional studies regarding this point need to be performed at cellular and molecular levels since the ciliary movement of a developing larva may not directly reflect the death of individual cells comprising it as the apoptosis of individual cells comprising an embryo did not surely cause death of the embryo (Park et al., 2020). As an another reason of efficiency difference of metaphase spread preparation by larval stage, we considered that there might be a difference of cell cycle distribution of the cells comprising larvae according to developmental stage since a higher portion of G2/M phase cells is eventually able to draw higher efficiency of metaphase spread preparation (Nkongolo and Klimaszewska, 1994; Yao et al., 2020). This hypothesis was tested by measuring DNA contents of the cells from trochophore and veliger larvae and as a result, we confirmed that there was no significant difference on the ratios of cells at each cell cycle phases between two developmental stages in both diploid and triploid larvae. This indicated that cell cycle distribution of the cells comprising larvae was not related to the efficiency difference of metaphase spread preparation by developmental stage. Collectively, the efficiency difference of metaphase spread preparation between trochophore and veliger stage larvae was obviously observed in this study even though a correctable cause about this has not been verified yet. Our results that both colchicine sensitivity and cell cycle distribution were not involved in such efficiency difference may indicate that the current protocol for metaphase spread preparation is not optimal to the cells from veliger stage larvae. Although a sufficient number of metaphase spreads for analysis could be obtained from veliger stage larvae even in the current efficiency, it needs to be increased for more universal use of them for karyotype analysis by optimizing the details of the protocol for metaphase spread preparation. Furthermore, considering the gravity of the environmental factors like the temperature for animal cells on the cellular physiological characteristics (Padilla-Gamiño et al., 2013; Choi and Gong, 2018), those also need to be experimentally optimized to increase the efficiency of metaphase spread preparation. On the other hands, we confirmed that the ratio of G0/ G1 and G2/M phases were altered by colchicine treatment. The role of colchicine in karyotype analysis is to arrest cell cycle progression of the cells at metaphase by inhibiting the formation of mitotic spindles so that much more cells that have metaphase chromosomes can be accumulated within the sample (Leung et al., 2015). In this regards, our results are very reasonable since those indicate that the colchicine treated to developing larvae operated appropriately.

Significant difference in the normality based on chromosome number was observed between diploid and triploid larvae regardless of developmental stage. Comparing with diploid larvae, triploid ones showed low chromosomal normality (48.6-54.3\% and 30.0-32.9\% normality in diploid and triploid, respectively). The cause of this can be deduced from the previous reports that showed the characteristics of triploid organisms (Henry et al., 2005; Park et al., 2018). A large amount of genome in the cells of triploid abalone larvae might increase aneuploidy by disturbing harmonious chromosome segregation. However, a sufficient number of metaphase spreads that have a normal chromosome number $(3 \mathrm{~N}=54)$ could be obtained in spite of low chromosomal normality suggesting its availability to analyze the karyotype of triploid abalone.

\section{CONCLUSIONS}

From this study, we confirmed that $H$. discus hannai veliger stage larvae are able to be used for karyotype analysis by demonstrating the feasibility of metaphase spread preparation from them. This indicates that the spectrum of sample collection for karyotype analysis can be expanded, which eventually increases the efficiency of analysis. Furthermore, it makes possible a stepwise evalu- 
ation of karyotype by developmental stage of the abalone, in which artificial breeding technology is applied.

\section{CONFLICTS OF INTEREST}

No potential conflict of interest relevant to this article was reported.

\section{ACKNOWLEDGEMENTS}

This research was supported by the grant from the Golden Seed Project (GSP), Ministry of Oceans and Fisheries to YKN (\#213008-05-3-SB620).

\section{AUTHOR CONTRIBUTIONS}

JHC performed the experiments and wrote the paper; EJK and CJP performed the experiments; YKN analyzed the data; SPG designed the experiments, analyzed the data and wrote the paper.

\section{AUTHOR'S POSITION AND ORCID NO.}

\author{
JH Choi, PhD Student, \\ https://orcid.org/0000-0003-3578-3167 \\ EJ Kim, PhD Student, \\ https://orcid.org/0000-0001-8303-1731 \\ CJ Park, PhD, Researcher, \\ https://orcid.org/0000-0001-8448-6957 \\ YK Nam, PhD, Professor, \\ https://orcid.org/0000-0001-8870-2098 \\ SP Gong, PhD, Professor, \\ https://orcid.org/0000-0002-9358-9568
}

\section{REFERENCES}

Allen Jr. SK and Downing SL. 1986. Performance of triploid Pacific oysters, Crassostrea gigas (Thunberg). I. Survival, growth, glycogen content, and sexual maturation in yearlings. J. Exp. Mar. Biol. Ecol. 102:197-208.

Arai K. 2001. Genetic improvement of aquaculture finfish species by chromosome manipulation techniques in Japan. Aquaculture 197:205-228.

Choi JH and Gong SP. 2018. Effects of temperatures and basal media on primary culture of the blastomeres derived from the embryos at blastula stage in marine medaka Oryzias dancena. J. Emb. Trans. 33:343-348.

Chung JK, Lim HK, Son MH, Kim JH, Jeong MH, Chang YJ.
2011. Effects of concentration and immersion time of three cryoprotective agents on the embryos development of abalone Haliotis discus hannai. Dev. Reprod. 15:301-308.

Dheilly NM, Jouaux A, Boudry P, Favrel P, Lelong C. 2014. Transcriptomic profiling of gametogenesis in triploid pacific oysters Crassostrea gigas: towards an understanding of partial sterility associated with triploidy. PLoS One 9:e112094.

Elliott NG. 2000. Genetic improvement programmes in abalone: what is the future? Aquac. Res. 31:51-59.

Ferm VH. 1963. Colchicine teratogenesis in hamster embryos. Porc. Soc. Exp. Biol. Med. 112:775-778.

Gallardo-Escárate C, Álvarez-Borrego J, Del Rio Portilla M, Kober V. 2004. Karyotype of pacific red abalone Haliotis rufescens (Archaeogastropoda: Haliotidae) using image analysis. J. Shellfish Res. 23:205-209.

Gallardo-Escárate C and del Río-Portilla M. 2007. Karyotype composition in three California abalones and their relationship with genome size. J. Shellfish Res. 26:825-832.

Henry IM, Dilkes BP, Young K, Watson B, Wu H, Comai L. 2005. Aneuploidy and genetic variation in the Arabidopsis thaliana triploid response. Genetics 170:1979-1988.

Hernández-Ibarra NK, Marquez C, Ramírez JL, Ibarra AM. 2004. Comparative karyotypes of two northeastern Pacific abalone species (Haliotis fulgens Philippi and Haliotis rufescens Swainson). J. Shellfish Res. 23:861-866.

Jee YJ and Chang YJ. 2012. Cytogenetic analysis of the triploid pacific abalone, Haliotis discus hannai. Korean J. Malacol. 28:37-43.

Karami A, Araghi PE, Syed MA, Wilson SP. 2015. Chromosome preparation in fish: effects of fish species and larval age. Int. Aquat. Res. 7:201-210.

Lee SY, Park CJ, Nam YK. 2019. Assessment of suitable reference genes for RT-qPCR normalization with developmental samples in pacific abalone Haliotis discus hannai. J. Anim. Reprod. Biotechnol. 34:280-291.

Leung YY, Yao Hui LL, Kraus VB. 2015. Colchicine--update on mechanisms of action and therapeutic uses. Semin. Arthritis Rheum. 45:341-350.

Nkongolo KK and Klimaszewska K. 1994. Karyotype analysis and optimization of mitotic index in Picea mariana (black spruce) preparations from seedling root tips and embryogenic cultures. Heredity 73:11-17.

Padilla-Gamiño JL, Kelly MW, Evans TG, Hofmann GE. 2013. Temperature and $\mathrm{CO}_{2}$ additively regulate physiology, morphology and genomic responses of larval sea urchins, Strongylocentrotus purpuratus. Proc. Biol. Sci. 280:20130155.

Park CJ, Kwon MS, Kim EJ, Nam YK. 2018. Improvement of cold-shock treatment conditions for triploidy induction in Pacific abalone Haliotis discus hannai. Korean J. Malacol. 34:191-200.

Park S, Song G, Lim W. 2020. Anti-developmental effects of imazosulfuron on zebrafish embryos during development. J. Anim. Reprod. Biotechnol. 35:28-34.

Piferrer F, Beaumont A, Falguière JC, Flajšhans M, Haffray $P$, Colombo L. 2009. Polyploid fish and shellfish: production, 
biology and applications to aquaculture for performance improvement and genetic containment. Aquaculture 293:125-156.

Pozarowski P and Darzynkiewicz Z. 2004. Analysis of cell cycle by flow cytometry. Methods Mol. Biol. 281:301-311.

Ryu JH, Lee SY, Nam YK, Gong SP. 2018. Non-lethal method for the preparation of metaphase spreads using cultured mantle tissue from live adult abalone. Biotechniques 65:33-36.

Wang H, Luo X, You W, Dong Y, Ke C. 2015. Cytogenetic analysis and chromosomal characteristics of the polymorphic $18 \mathrm{~S}$
rDNA of Haliotis discus hannai from Fujian, China. PLoS One 10:e0113816.

Yang XM, Cao ZY, An LZ, Wang YM, Frang XW. 2006. In vitro tetraploid induction via colchicine treatment from diploid somatic embryos in grapevine (Vitis vinifera L.). Euphytica 152:217-224.

Yao Y, Zhang Y, Liu W, Deng X. 2020. Highly efficient synchronization of sheep skin fibroblasts at G2/M phase and isolation of sheep Y chromosomes by flow cytometric sorting. Sci. Rep. 10:9933. 